\title{
periferio
}

\section{EXPERIÊNCIAS DE FORMAÇÃO CONTINUADA DE PROFESSORES: POSSIBILIDADES PARA EFETIVAR A INCLUSÃO ESCOLAR DE ALUNOS COM DEFICIÊNCIA INTELECTUAL ${ }^{1}$}

\author{
Márcia Denise Pletsch² \\ Universidade Federal Rural do Rio de Janeiro/IM \\ Daniele Francisco de Araújo 3 \\ Universidade Federal Rural do Rio de Janeiro/ObEE \\ Marcela Francis Costa Lima ${ }^{4}$ \\ Universidade Federal Rural do Rio de Janeiro/PPGEDUC
}

\section{Resumo}

Este texto discute a formação continuada de professores frente às demandas colocadas pelas atuais políticas de inclusão escolar dirigidas para pessoas com deficiências, em particular, com deficiência intelectual. Para tal, toma como referência a análise qualitativa de um Programa de Formação Continuada pelo Grupo de Pesquisa Observatório de Educação Especial e Inclusão Educacional (ObEE/UFRRJ), realizado no ano de 2015. A pesquisa contou com a participação de 120 professores de sete redes municipais de ensino da Baixada Fluminense/RJ. Os resultados, analisados a partir da perspectiva histórico-cultural, evidenciaram que, apesar da existência de diretrizes federais favoráveis a uma política de educação mais inclusiva, as redes municipais têm implementado ações e formações muito diversas entre si. Outro dado diz respeito à importância de formações continuadas que possibilitem a participação ativa dos professores na construção de propostas pedagógicas, assim como a necessidade de ampliar ações articuladas entre a Universidade e a Educação Básica.

Palavras-chave: políticas de educação inclusiva; formação continuada de professores; deficiência intelectual

\footnotetext{
${ }^{1}$ Financiamento: CAPES, FAPERJ e CNPq. A análise completa desse programa foi apresenta das dissertações de Araújo (2016) e Lima (2017).

2 Doutora em Educação. Professora Associada do Departamento Educação e Sociedade e do Programa de Pós-Graduação em Educação, Contextos Contemporâneos e Demandas Populares - PPGEduc - da Universidade Federal Rural do Rio de Janeiro - UFRRJ. Jovem Cientista do Nosso Estado da FAPERJ e Pesquisadora do CNPq. marciadenisepletsch@gmail.com

3 Mestre em Educação pelo Programa de Pós-graduação em Educação, Contextos Contemporâneos e Demandas Populares - PPGEduc - da Universidade Federal Rural do Rio de Janeiro; Bolsista de Treinamento e Capacitação Técnica da FAPERJ. dany_araujo100@hotmail.com

${ }^{4}$ Doutoranda e Mestre em Educação pelo Programa de Pós-graduação em Educação, Contextos Contemporâneos e Demandas Populares -PPGEduc - da Universidade Federal Rural do Rio de Janeiro; Bolsista FAPERJ. marcela.fcl@gmail.com
} 


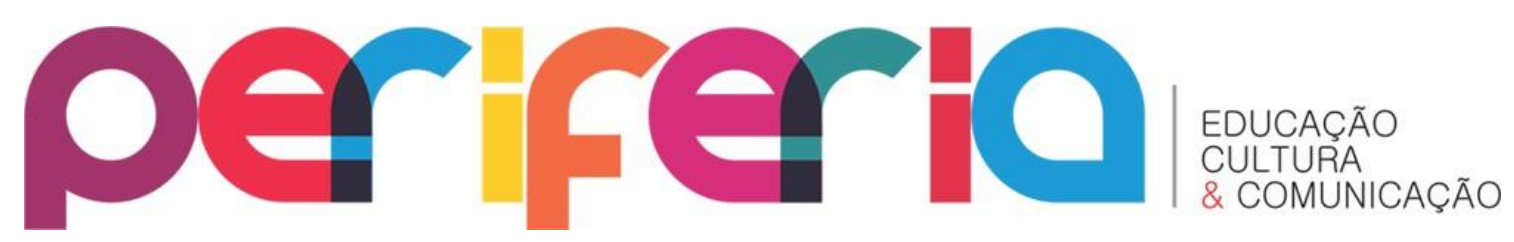

\title{
EXPERIENCES OF CONTINUING TEACHERS EDUCATION: POSSIBILITIES FOR EFFECTIVE INCLUSION OF STUDENTS WITH INTELLECTUAL DISABILITIES
}

\begin{abstract}
This text discusses the ongoing formation of teachers in response to the demands placed by the current policies of school inclusion directed to people with disabilities, in particular, with intellectual disabilities. To do so, it takes as reference the qualitative analysis of a Continuing Education Program by the Observatory Research Group on Special Education and Educational Inclusion (ObEE / UFRRJ), held in 2015. The research was attended by 120 teachers from seven networks Municipalities of Baixada Fluminense / RJ. The results, analyzed from the historical-cultural perspective, showed that, despite the existence of federal guidelines favorable to a more inclusive education policy, municipal networks have implemented actions and formation programs that are very diverse among them. Another aspect concerns the importance of continuous training that enables the active participation of teachers in the construction of pedagogical proposals, as well as the need to expand articulated actions between the University and Basic Education.
\end{abstract}

Keywords: inclusive education policies; continuing teacher training; intellectual disability 


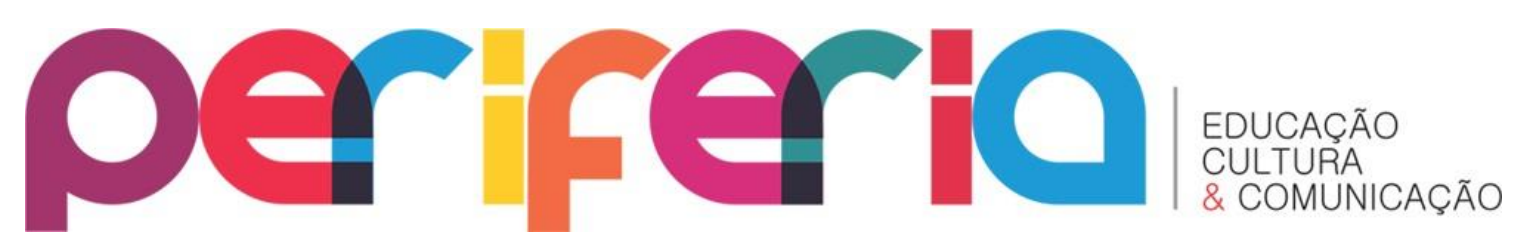

\section{CONTEXTUALIZANDO A PESQUISA}

Com a implementação da Política Nacional de Educação Especial na Perspectiva da Educação Inclusiva (BRASIL, 2008) e das Diretrizes Operacionais do Atendimento Educacional Especializado na Educação Básica, modalidade Educação Especial (BRASIL, 2009) temos vivenciado diferentes mudanças no que diz respeito a escolarização dessa população (pessoas com deficiências intelectual, sensorial, transtornos globais do desenvolvimento e altas habilidades/superdotação). Esses documentos evidenciam que a inclusão deve se dar em todos os níveis de ensino, desde a educação infantil até o ensino superior. Igualmente, indicam que o suporte educacional especializado deve ocorrer, prioritariamente, em salas de recursos multifuncionais por meio do Atendimento Educacional Especializado (AEE), entendido como complemento e suplemento ao ensino comum e não como espaço substitutivo de escolarização, conforme ocorria - e ainda ocorre - em escolas especiais e nas classes especiais (BRASIL, 2008; 2009). 0 referido Atendimento Educacional Especializado deve ocorrer nas salas de recursos multifuncionais, espaços equipados com recursos pedagógicos e tecnologias assistivas. Tais tecnologias são entendidas no Brasil como materiais de trabalho especialmente desenhados ou adaptados; elementos de mobilidade, cuidado e higiene pessoal requeridos para a autonomia e a segurança; elementos especiais para facilitar a comunicação, a informação e a sinalização; adaptações ambientais e outras que garantam o acesso, a melhoria funcional e a autonomia pessoal (BRASIL, 2007).

Tomando essa realidade como pano de fundo, este texto discute algumas dimensões que envolvem a formação continuada de professores frente às demandas colocadas pelas atuais políticas de inclusão escolar dirigidas para pessoas com deficiências. Ênfase especial é dada aos caminhos encontrados pelos docentes em suas práticas cotidianas para ampliar as 


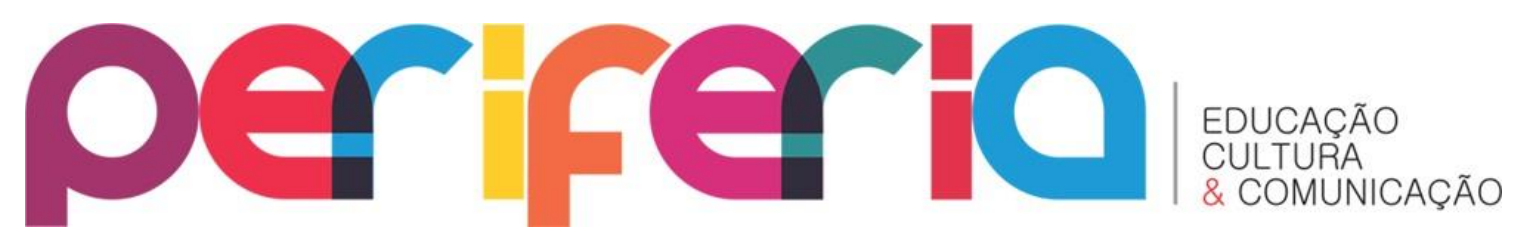

possibilidades de escolarização de alunos com deficiência intelectual, ${ }^{5}$ que hoje abarcam cerca de 70\% das matrículas da Educação Especial no Brasil. Cabe mencionar que, apesar dos avanços legais, essa população de aproximadamente 611.917 dos quais 448.503 estão matriculados em classes comuns de ensino (BRASIL, 2015). Ou seja, mais da metade dos alunos da Educação Especial matriculados (incluídos) em classes comuns da Educação Básica é constituída por pessoas que apresentam deficiência intelectual. Segundo Mendes et al (2016) "além de ser o maior contingente do alunado, o fato da natureza do déficit ser na área cognitiva, fazem com que dos alunos do público-alvo da Educação Especial, esses alunos são os que causam mais dúvidas e desafios ao espaço educacional" (p.51). Nossas pesquisas e as de Braun (2012), Marin (2015) e Braun e Marin (2016) corroboram com esse dado.

Neste contexto, o Grupo de Pesquisa Observatório de Educação Especial $e$ Inclusão Educacional (ObEE/UFRRJ), vinculado ao Programa de PósGraduação em Educação, Contextos Contemporâneos e Demandas Populares da Universidade Federal Rural do Rio de Janeiro (PPGEduc/UFRRJ), vem analisando um conjunto de práticas curriculares e os processos de ensino e aprendizagem dirigidos para a população que constitui no Brasil o público alvo da Educação Especial (pessoas com deficiências, transtornos globais do desenvolvimento e altas habilidades/superdotação). 0 foco de nossos estudos tem sido o alunado com deficiência intelectual e múltipla. Igualmente, tem analisado a formação continuada de professores.

O ObEE tem trabalhado com o conceito de inclusão escolar numa perspectiva ampla fundamentada nos princípios dos direitos humanos em que os sujeitos com deficiências tenham acesso à escola, participem das atividades ali realizadas e possam aprender e, consequentemente,

\footnotetext{
${ }^{5}$ Não é nosso objetivo discutir o conceito de deficiência intelectual, mas cabe esclarecer que adotamos as indicações da Associação Americana Associação Americana de Deficiência Intelectual e Desenvolvimento (AAIDD). De acordo com a entidade, a deficiência intelectual caracteriza-se por "limitações significativas tanto no funcionamento intelectual como na conduta adaptativa e está expresso nas habilidades práticas, sociais e conceituais, originandose antes dos dezoito anos de idade" (AAIDD, 2010, p.31).

${ }^{6}$ Disponível em: http://r1.ufrrj.br/im/oeeies/
} 


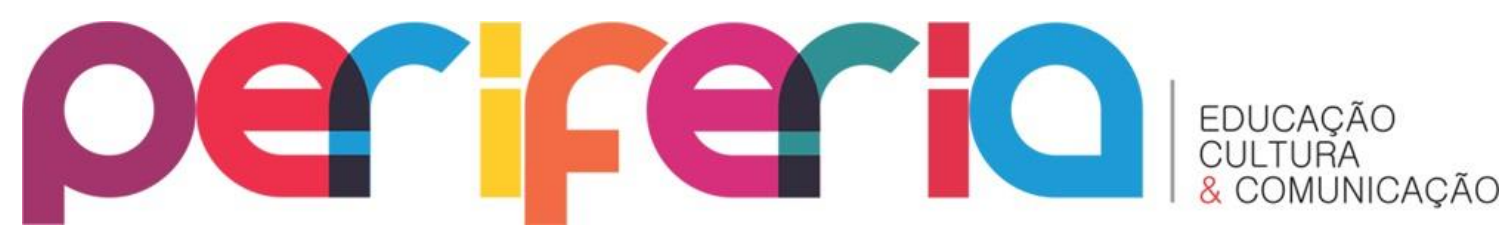

desenvolver-se a partir da pluralidade e diversidade cultural que constitui a escola na contemporaneidade. Assim, como Kassar (2016), entendemos o conceito de desenvolvimento humano fundamentado na perspectiva históricocultural de Vigostki (1984), o qual:

Concebe o desenvolvimento dos sujeitos como um processo complexo de apropriação, por cada indivíduo em sua particularidade, dos bens culturais socialmente produzidos pela humanidade em cada momento histórico. Portanto, o desenvolvimento humano é, ao mesmo tempo, um processo particular e coletivo/social, em que a aprendizagem impulsiona o desenvolvimento. Por essa perspectiva, as relações de ensino-aprendizagem inserem-se no âmbito das práticas sociais, por serem socialmente instituídas e significadas (KASSAR, 2016, p. 1231).

Com base nessa perspectiva compreendemos que a escola a partir de suas práticas curriculares tem papel determinante no desenvolvimento de seus alunos, sobretudo, no que diz respeito aos processos de ensino e aprendizagem elaborados e dirigidos para alunos com deficiência intelectual, pois "se a aprendizagem impulsiona o desenvolvimento, se desenvolvimento humano implica desenvolvimento cultural e se o desenvolvimento materializase num processo complexo de apropriação das práticas sociais e dos bens culturais socialmente produzidos, as práticas restritivas/colaboram para um desenvolvimento humano restritivo" (KASSAR, 2016, p. 1234).

Em outras palavras, as possibilidades de incorporação da cultura pelas pessoas com deficiência intelectual, assim como de qualquer pessoa, dependem das interações estabelecidas entre professor e aluno e/ou aluno e aluno durante as práticas pedagógicas, bem como dessas práticas em si e de suas condições concretas de vida (materiais, orgânicas e psicológicas). Portanto, para que possibilitem aos alunos com deficiência intelectual desenvolver novas formas de funcionamento mental, as atividades escolares devem priorizar o ensino dos conceitos, seus significados e sentidos. Isto é, no caso específico do público deste artigo, entendemos que o uso de recursos e estratégias diferenciadas nas práticas curriculares a partir de planejamentos 


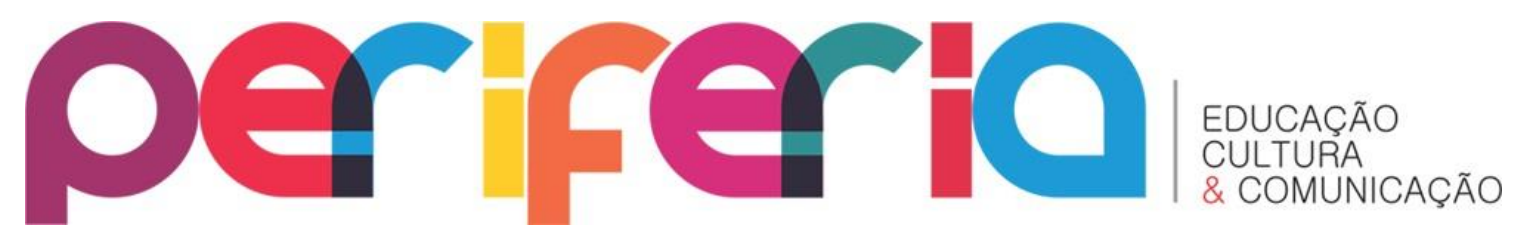

articulados com o currículo em geral é fundamental e, em muitos casos, imprescindível. Por outro lado, não podemos negar que em casos mais graves de deficiência, faz-se necessário pensar novas possibilidades de escolarização levando em consideração novas "formas de participação e interação com o meio social para que desenvolvam novos modos de ser e agir" (PLETSCH, 2014, p. 13). Essa defesa é possível a partir da análise sobre os processos psicológicos superiores presente na perspectiva histórico-cultural de Vigotski, que sinalizam para a complexidade do desenvolvimento humano, mesmo quando o sujeito realiza atividades consideradas simples e repetitivas.

A este respeito, Kassar (2013) sinaliza que a aprendizagem está relacionada com as oportunidades que são oferecidas aos sujeitos. Isto é, mesmo quando consideramos determinadas aprendizagens elementares, primárias ou repetitivas, elas podem envolver processos psicológicos complexos para estes ou aqueles sujeitos dependendo das suas condições concretas de existência, mas não podemos esquecer que "o ser humano não apenas é ou está, mas se constitui como um vir a ser" (PLETSCH, 2015, p. 22).

Tomando tais referenciais como pano de fundo temos promovido pelo ObEE ações que articulam pesquisa e extensão para a formação de professores focando as propostas de educação inclusiva de pessoas com deficiência.

\section{ASPECTOS METODOLÓGICOS: LÓCUS, SUJEITOS E PROCEDIMENTOS DE PESQUISA}

Em termos metodológicos, cabe destacar que se tratam de pesquisa qualitativas que tem adotado como, entre outros, procedimentos de coleta de dados a observação participante, filmagens de práticas pedagógicas desenvolvidas em salas de aula e entrevistas semiestruturadas com gestores educacionais das sete redes municipais da Baixada Fluminense/RJ/Brasil, totalizando 120 professores participantes do Programa de Formação Continuada intitulado "Processos de ensino e aprendizagem de alunos com deficiência intelectual", com duração de 120 horas desenvolvidas no ano de 2015. 0 quadro sintetiza essas atividades presenciais e à distância. 


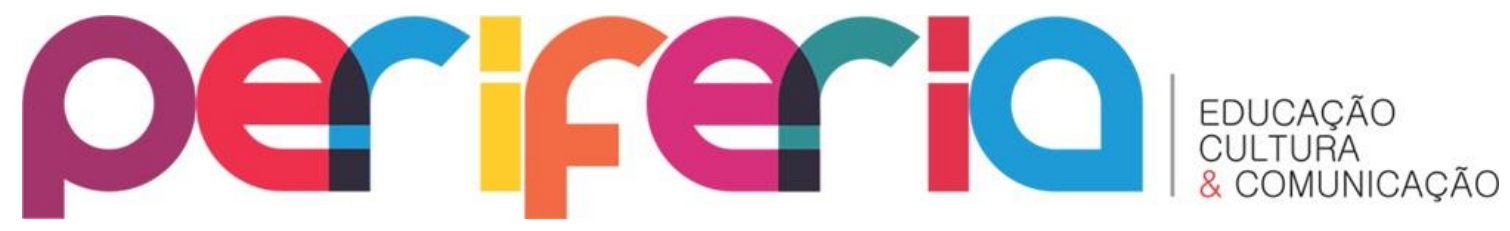

\section{Quadro 1: Estruturação do Programa de Formação Continuada}

\begin{tabular}{|c|c|c|c|}
\hline \multicolumn{2}{|c|}{ Estrutura do curso } & Data & Temática \\
\hline \multirow{13}{*}{$\begin{array}{l}\text { Modalidade } \\
\text { Presencial }\end{array}$} & $1^{\mathrm{a}}$ aula & $26 / 03 / 2015$ & História e políticas públicas em Educação Especial \\
\hline & $2^{\mathrm{a}}$ aula & $09 / 04 / 2015$ & $\begin{array}{l}\text { Educação Inclusiva na pauta dos direitos humanos: } \\
\text { traços históricos e normativas políticas }\end{array}$ \\
\hline & $3^{\mathrm{a}}$ aula & $30 / 04 / 2015$ & Gênese da perspectiva histórico-cultural \\
\hline & $4^{\mathrm{a}}$ aula & $07 / 05 / 2015$ & $\begin{array}{l}\text { Ensino e aprendizagem de pessoas com deficiência } \\
\text { intelectual e múltipla }\end{array}$ \\
\hline & $5^{\mathrm{a}}$ aula & $21 / 05 / 2015$ & Currículo e adaptações curriculares \\
\hline & $6^{\mathrm{a}}$ aula & 09/06/2015 & $\begin{array}{l}\text { Tecnologias assistivas e mediação: } \\
\text { múltipla }\end{array}$ \\
\hline & $7^{\mathrm{a}}$ aula & $23 / 06 / 2015$ & Conceito da compensação \\
\hline & $8^{\mathrm{a}}$ aula & $02 / 07 / 2015$ & $\begin{array}{l}\text { Trabalho colaborativo entre o professor da sala } \\
\text { comum e o professor de AEE }\end{array}$ \\
\hline & $9^{\mathrm{a}}$ aula & $16 / 07 / 2015$ & $\begin{array}{l}1^{\text {a }} \text { parte: Atendimento pedagógico domiciliar } \\
2^{\text {a }} \text { parte: Atendimento educacional especializado }\end{array}$ \\
\hline & $10^{\mathrm{a}}$ aula & $04 / 08 / 2015$ & Planejamento Educacional Individualizado (PEI) \\
\hline & $11^{\mathrm{a}}$ aula & $18 / 08 / 2015$ & Família e deficiência \\
\hline & $12^{\mathrm{a}}$ aula & $01 / 09 / 2015$ & Metodologia da pesquisa-ação \\
\hline & $13^{\mathrm{a}}$ aula & $15 / 09 / 2015$ & 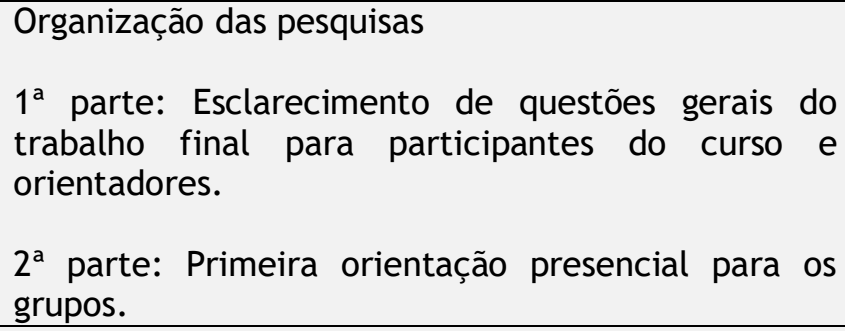 \\
\hline $\begin{array}{l}\text { Modalidade } \\
\text { à Distância }\end{array}$ & $\begin{array}{l}\text { Orientaç } \\
\text { ão dos } \\
\text { trabalho } \\
\text { s finais; } \\
\text { Seminár } \\
\text { ios nas } \\
\text { redes }\end{array}$ & $\begin{array}{l}\text { Outubro e } \\
\text { novembro }\end{array}$ & $\begin{array}{l}\text { Organização e desenvolvimento do trabalho final, } \\
\text { com prévia apresentada em seminários promovidos } \\
\text { pelas redes municipais de educação. } \\
\text { Os professores orientadores auxiliaram neste } \\
\text { processo. }\end{array}$ \\
\hline \multirow{2}{*}{\multicolumn{2}{|c|}{$\begin{array}{l}\text { SEMINÁRIO DE } \\
\text { ENCERRAMENTO } \\
\text { DO PROGRAMA: } \\
\text { Processos de ensino e } \\
\text { aprendizagem de } \\
\text { pessoas } \\
\text { com deficiência } \\
\text { intelectual }\end{array}$}} & $02 / 12 / 1015$ & $\begin{array}{l}\text { Apresentação dos projetos de intervenção; } \\
\text { Certificação e premiação dos quatro melhores. }\end{array}$ \\
\hline & & 03/12/1015 & $\begin{array}{l}\text { Apresentação dos projetos de intervenção; } \\
\text { Certificação e premiação dos quatro melhores. } \\
\text { Gravações de depoimentos sobre o curso, } \\
\text { com alguns sujeitos da pesquisa. }\end{array}$ \\
\hline
\end{tabular}

Fonte: Elaborado por Araújo (2016) a partir do banco de dados do ObEE. 


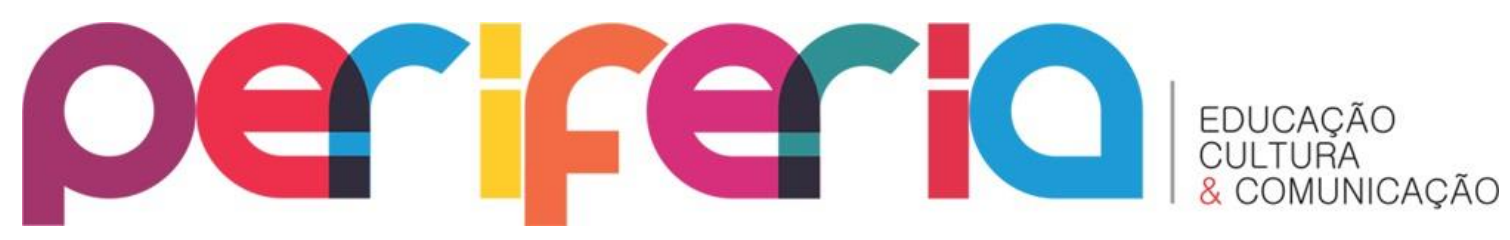

Em relação ao Programa de Formação Continuada é importante sinalizar que o mesmo integrou as ações de dois projetos de pesquisa. 0 primeiro, desenvolvido por uma rede de pesquisadores ${ }^{7}$, foi financiado pelo Programa Observatório da Educação da Coordenação de Aperfeiçoamento de Pessoal de Nível Superior (CAPES) em 2012, intitulado “A escolarização de alunos com deficiência intelectual: políticas públicas, processos cognitivos e avaliação da aprendizagem". Seu objetivo consistia na análise das "dimensões que envolvem a escolarização de alunos com deficiência intelectual que frequentam a escola comum e recebem, paralelamente, atendimento educacional especializado em sala de recursos multifuncionais destinadas a apoiar os processos de inclusão escolar desse público-alvo" (PLETSCH, MENDES \&HOSTINS, 2012).

O segundo teve sua aprovação mais recentemente, em 2015, e intitulase "Escolarização e desenvolvimento de alunos com deficiência intelectual e múltipla na Baixada Fluminense" com financiamento da Fundação Carlos Chagas Filho de Amparo à Pesquisa do Estado do Rio de Janeiro (FAPERJ) e do Conselho Nacional de Desenvolvimento Científico e Tecnológico (CNPq). Seu objetivo é acompanhar a escolarização de alunos com deficiência intelectual e múltipla, a fim de analisar o desenvolvimento desses sujeitos e o papel desempenhado pelo atendimento educacional especializado em seis municípios da Baixada Fluminense/RJ. Também é um dos objetivos do projeto realizar um mapeamento da participação desses sujeitos nas avaliações oficiais (PLETSCH, 2015).

O perfil dos participantes foi sintetizado no quadro a seguir.

\footnotetext{
${ }^{7}$ Participaram pesquisadores de três Programas de Pós-Graduação em Educação, a saber: da Universidade Federal Rural do Rio de Janeiro (UFRRJ), da Universidade do Estado de Santa Catarina (UDESC) e da Universidade do Vale do Itajaí (UNIVALI).
} 


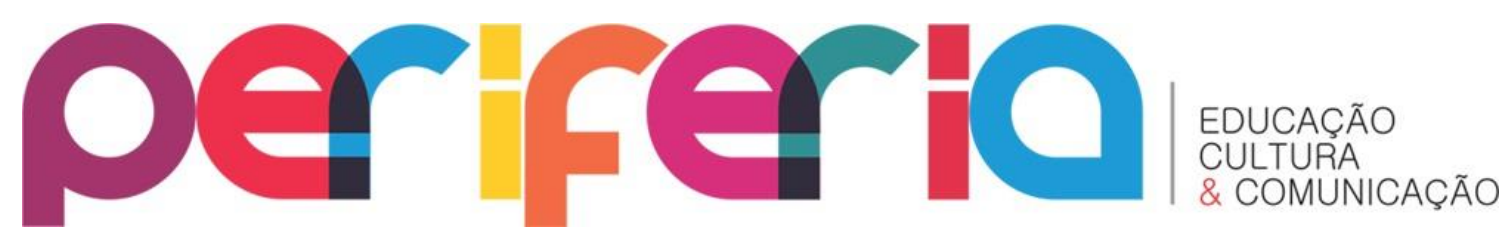

Quadro 2: Perfil formativo dos participantes ${ }^{8}$ do Programa de Formação Continuada

\begin{tabular}{|c|c|c|c|}
\hline \multirow{3}{*}{ Nível Superior } & \multirow{3}{*}{ Graduação } & Em Pedagogia & $54^{9}$ \\
\hline & & Em outras licenciaturas & 24 \\
\hline & & Em outras graduações ${ }^{10}$ & 09 \\
\hline Pós-médio & Normal Superior & Normal Superior & 01 \\
\hline \multirow{3}{*}{ Nível médio } & \multirow{3}{*}{ Curso Normal } & E Graduação em Pedagogia & 05 \\
\hline & & $\begin{array}{lrlr}\text { E } & \text { Graduação } & \text { em } & \text { outras } \\
\text { licenciaturas } & & \end{array}$ & 08 \\
\hline & & Curso Normal & 17 \\
\hline
\end{tabular}

Fonte: Elaborado por Araújo (2016) a partir do banco de dados do ObEE.

Sobre a Baixada Fluminense cabe dizer que integra a região metropolitana do Rio de Janeiro, com uma extensão territorial de $3152 \mathrm{~km} 2$ e possui uma população de, aproximadamente, quatro milhões de habitantes, distribuída em seus treze municípios, a saber: Belford Roxo, Duque de Caxias, Guapimirim, Itaguaí, Japeri, Magé, Mesquita, Nilópolis, Nova Iguaçu, Paracambi, Queimados, Seropédica e São João de Meriti (IBGE, 2015). Para este artigo analisaremos apenas os Planos Municipais de Educação dos sete municípios que participam de nossas pesquisas na atualidade: Nova Iguaçu, São João de Meriti, Belford Roxo, Nilópolis, Queimados, Duque de Caxias e Mesquita (ObEE, 2016).

Conforme já sinalizamos em outro artigo a realidade social da região é marcada por baixos índices de desenvolvimento humano (IDH), evasão escolar, precariedade nos serviços de saúde e outros problemas comuns às grandes metrópoles brasileiras, como falta de saneamento básico, precariedade do transporte público e a violência urbana (PLETSCH, 2016). O quadro a seguir sintetiza alguns indicadores da região:

\footnotetext{
${ }^{8}$ Apenas uma pessoa não especificou sua formação inicial.

9 Três pessoas informaram que possuem formação em Pedagogia e em outro curso de Licenciatura.

10 Quanto as outras graduações temos os seguintes cursos: Psicologia, Fonoaudiologia, Fisioterapia, Comunicação social e Publicidade.
} 


\section{periferio}

Quadro 3: Indicadores da Baixada Fluminense ${ }^{11}$

\begin{tabular}{|l|l|l|l|l|}
\hline & $\begin{array}{l}\text { População } \\
\text { estimada em } \\
2015\end{array}$ & $\begin{array}{l}\text { IDH } \\
2010\end{array}$ & $\begin{array}{l}\text { Total de } \\
\text { alunos }\end{array}$ & $\begin{array}{l}\text { Total de alunos } \\
\text { da Educação } \\
\text { Especial }\end{array}$ \\
\hline Duque de Caxias & 882.729 & 0,711 & 75.030 & 2.315 \\
\hline Belford Roxo & 481.127 & 0,684 & 42.000 & 918 \\
\hline São João de Meriti & 460.625 & 0,719 & 31.712 & 787 \\
\hline Mesquita & 170.751 & 0,737 & 25.659 & 407 \\
\hline Queimados & 143.632 & 0,680 & 13.054 & 407 \\
\hline Nova Iguaçu & 807.492 & 0,713 & 58.886 & 1.110 \\
\hline Nilópolis & 158.309 & 0,753 & 28.769 & 315 \\
\hline
\end{tabular}

Fonte: Elaborado por Pletsch (2016) a partir do banco de dados ObEE (2013-2015).

Como procedimentos de coleta de dados, neste texto, priorizamos aqueles coletados conforme estruturado e descrito por Araújo (2016, p. 70):

a) Dois questionários semiestruturados. Os questionários foram aplicados ao longo do Programa de Formação Continuada, sendo um no início do Programa com a finalidade de conhecer o perfil docente participante, assim como coletar informações acerca dos conhecimentos sobre educação especial e inclusiva e conceitos da perspectiva histórico-cultural de Vigotski. $\mathrm{O}$ segundo questionário, aplicado ao final, teve por finalidade reconhecer e refletir sobre os conhecimentos apreendidos ou não;

b) Trabalhos de conclusão de curso, que chamamos de projetos de intervenção. Todos os participantes do Programa pesquisaram e elaboraram um projeto de intervenção que consistiu nos seguintes passos: 1) identificação de uma situação problema de um aluno com deficiência intelectual ou múltipla em uma realidade escolar, 2) elaboração de uma proposta de intervenção para "solucionar" o problema. Os projetos foram realizados em grupos por redes de ensino, tendo cada rede um orientador para suporte. Os orientadores foram os componentes mestrandos, mestres e doutorandos do grupo de pesquisa ObEE;

11 Cabe destacar que pode haver pequenas diferenças entre os dados apresentados nos quadros, pois os mesmos foram coletados em anos diferentes. Todavia, entendemos que essas mudanças não impactam nas análises realizadas. 


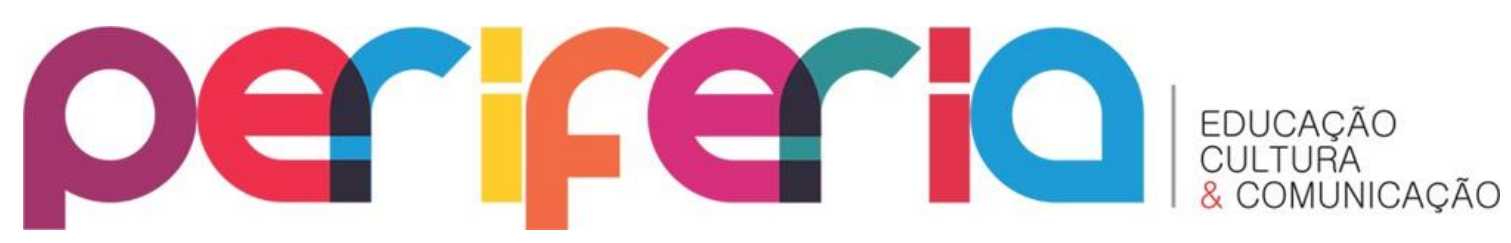

c) Vídeos com depoimentos de 13 participantes sobre o Programa de Formação Continuada;

d) Diários de campo com registros sobre os acontecimentos do curso.

Para a análise dos dados o grupo do ObEE tem priorizado a análise de conteúdo de Bardin (2009) presente em diversas pesquisas qualitativas em Educação Especial (ARAÚJO, 2016). De acordo com as indicações da análise de conteúdo a análise de dados deve seguir três etapas: pré-análise, exploração de material e interpretação de dados. A primeira consiste em organizar e sistematizar os dados a partir dos objetivos da investigação. Na segunda etapa os dados são catalogados e codificados. Na terceira etapa faz-se a interpretação dos dados triangulando os dados de campo, aliados aos aspectos teóricos e a literatura especializada.

A partir desses cuidados metodológicos organizamos, neste artigo, dois eixos temáticos articulados entre si, a saber: a) Formação de professores no contexto das políticas de inclusão escolar; e b) Caminhos encontrados pelos docentes em suas práticas cotidianas para ampliar as possibilidades de escolarização de alunos com deficiência intelectual.

\section{RESULTADOS DA PESQUISA}

A formação de professores ou a não formação tem sido constante nos debates e pesquisas sobre a implementação das políticas de inclusão escolar. Para Kassar (2014) não temos consensos sobre qual deveria ser a formação de professores para atuar na Educação Especial numa perspectiva inclusiva. $\mathrm{Na}$ análise da autora diferentes aspectos que ultrapassam especificidades da área precisam ser levados em consideração quando falamos de formação de professores para atuar com o público da Educação Especial, como, por exemplo, a crescente privatização do ensino superior, sobretudo, nas regiões sul e sudeste do Brasil.

A autora também chama atenção para o fato de que ao mesmo tempo em que temos um aumento significativo nas matrículas de alunos com 


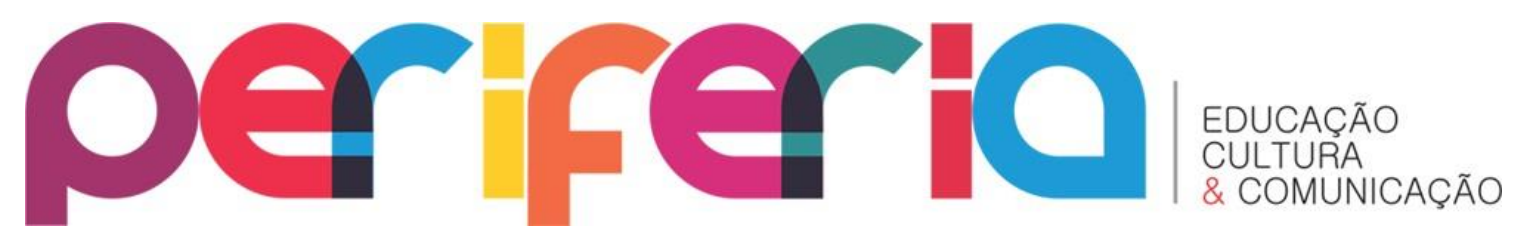

deficiências nas escolas comuns, temos, por outro lado, uma diminuição da oferta de cursos específicos. A insatisfação com a formação profissional recebida para atuar com o público da Educação Especial, sobretudo, para quem atua no $\mathrm{AEE}$, também foi verificada junto a 1.202 professores de 150 cidades brasileiras durante a pesquisa do Observatório Nacional de Educação Especial (ONEESP) (MENDES et al, 2016).

Os dados da investigação realizada pelo ONEESP mostram que $43,6 \%$ dos professores concordam parcialmente que estejam preparados para lidar com a diversidade de alunos que constituem a Educação Especial, enquanto apenas $7,5 \%$ consideram-se totalmente aptos. Os demais, $48,9 \%$, dizem não se sentir preparados ao responder à pergunta com discordo totalmente, discordo parcialmente e de que não concorda e nem discorda.

Diante dessas questões parafraseamos Kassar (2014, p. 218) "Que tipo de conhecimento é relevante para uma formação do professor da educação básica, levando-se em conta a escolarização dos alunos com deficiências? Que tipo de conhecimento é necessário para formar o professor considerado “especialista'?". A estas questões acrescentamos aquelas trazidas por Araújo (2016): Qual seria a formação necessária para atender as demandas da Educação Especial na atualidade?

De acordo com os dados coletados ao longo do Programa de Formação Continuada, $32,7 \%$ do público docente participante não possui nenhuma formação em educação especial ou educação inclusiva, conforme aponta o gráfico a seguir: 


\section{periferio}

Gráfico 1: Formação do público docente na perspectiva da educação inclusiva do Programa de Formação Continuada

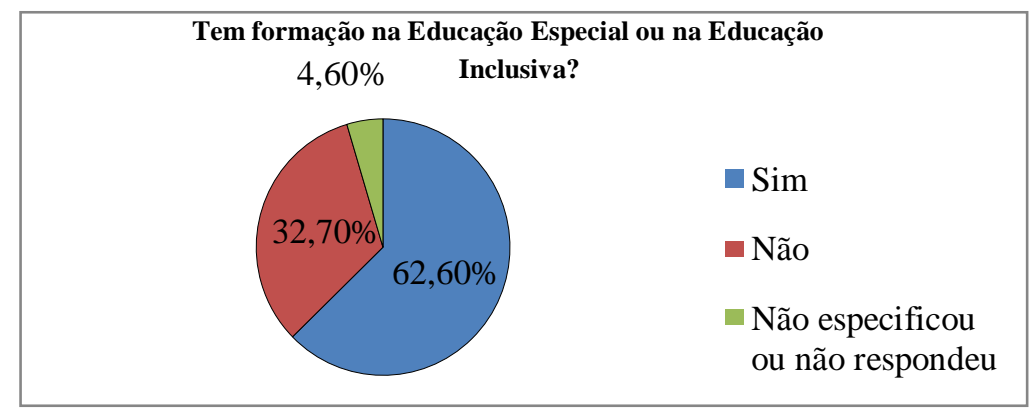

Fonte: Elaborado por Araújo (2016, p. 82) a partir do banco de dados do ObEE.

São dados preocupantes levando em consideração que entre o público do Programa de Formação Continuada encontram-se orientadores pedagógicos e educacionais, gestores de escolas e das coordenadorias de educação especial de alguns dos municípios participantes dos projetos de pesquisas, porém a maior parte diz respeito à professores de sala de aula comum com alunos com deficiências em suas turmas e também de professores de atendimento educacional especializado.

Outro dado interessante se refere a estes $62,6 \%$ que possuem formação em educação especial ou educação inclusiva, em que aproximadamente a metade $(30,9 \%)$ informou que toda ou parte dessa formação foi através de pós-graduação a nível de especialização em educação especial.

Cabe salientar que realizar um curso de pós-graduação tanto público quanto privado envolve, além da formação continuada, a busca pelo desenvolvimento profissional, tendo em vista que esses cursos são realizados por instituições de ensino autorizadas pelo MEC. Dito isso, trazemos o panorama $^{12}$ da formação continuada dos municípios da Baixada Fluminense que participam dos projetos de pesquisa no período compreendido entre 2012 e 2016. As formações foram sistematizadas de acordo a definição presente nas Diretrizes Curriculares Nacionais para a Formação Inicial em Nível Superior e para a Formação Continuada (BRASIL, 2015a).

\footnotetext{
12 Para maiores detalhes sobre o panorama formativo completo, ver Araújo (2016, p. 144).
} 


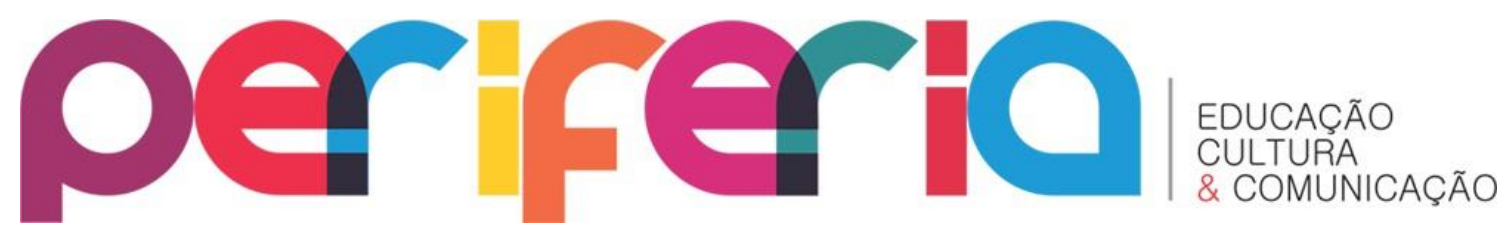

Gráfico 2: Panorama formativo das redes dos municípios da pesquisa (2012-2016)

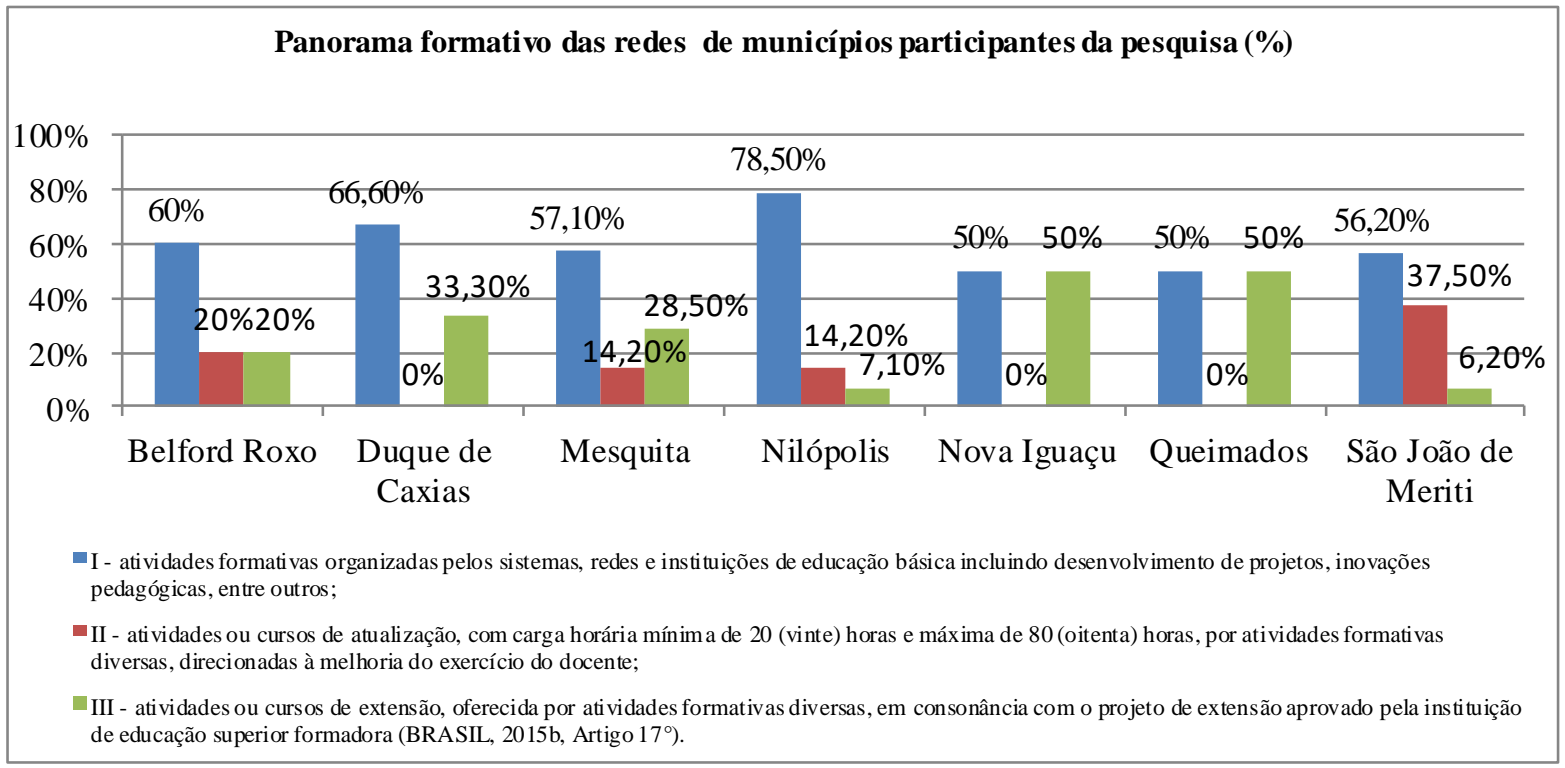

Fonte: Elaborado por Araújo (2016, p. 84) a partir do banco de dados do ObEE.

De acordo com os dados, a maioria das formações se concentra em atividades organizadas pelas secretarias de educação, sob égide das coordenadorias municipais de educação especial. No caso das redes municipais de educação participantes, a maioria das formações concentra-se na atividade formativa I, conforme aponta o gráfico 2. São formações realizadas na forma de encontros, palestras ou seminários pontuais com temas, cuja secretaria de educação e/ou educação especial convida pessoas especialistas ou com experiência docente naquele tema para ministrar a atividade formativa.

Na maioria dos casos não há a necessidade de uma tarefa prática, que possibilite maior apreensão do tema exposto, caracterizando-se por formações teóricas de racionalidade técnica (FERREIRA, 2007). Segundo Avila, Trigueiro e Silva (2016, p. 3), essa “cultura das políticas de formação dos sistemas de ensino ainda não priorizam as formações continuadas com objetivo de formar e sim apenas de informar", aumentando assim a frustração e até mesmo o não-interesse docente em fazer parte, o que implica 


\section{periferio}

diretamente nas práticas e processos de ensino e aprendizagem direcionados aos alunos.

Com relação aos caminhos encontrados pelos docentes em suas práticas cotidianas para ampliar as possibilidades de escolarização de alunos com deficiência intelectual verificamos que apesar da existência de diretrizes federais favoráveis a uma política de educação mais inclusiva, sua implementação no cotidiano das escolas tem sido muito diversas entre si, assim como as estratégias e suportes oferecidos para a escolarização destes sujeitos.

Uma das possibilidades que identificamos nos dados e que chamou nossa atenção diz respeito ao que temos denominado, em concordância com Ferreira (2007), como princípio de letramento na organização e sistematização de um currículo diversificado. De acordo com a interpretação da autora, essa perspectiva possibilitaria ao professor desenvolver diferentes possibilidades de atuação para o desenvolvimento das funções psicológicas superiores dos alunos em seu desenvolvimento escolar em particular. Em suas palavras, o letramento "parece ser uma alternativa que orienta o percurso educacional de forma a viabilizar as condições de educação necessárias ao muito do que tais alunos podem vir a ser" (p. 107). Essa perspectiva foi identificada em propostas envolvendo o Planejamento Educacional Individualizado (PEI) (AVILA, 2016; CAMPOS, 2016).

Dando continuidade à nossa discussão, e aos dados obtidos em nossa investigação, nos reportamos as perguntas realizadas ${ }^{13}$ para conhecer como os profissionais que atuam com os alunos com deficiência intelectual entendem a perspectiva histórico-cultural. As perguntas foram direcionadas ao conhecimento sobre a perspectiva histórico-cultural e alguns de seus conceitos como os de mediação, processos psicológicos superiores e a relação signo e linguagem. As opções de respostas eram sim, não ou nunca ouvi falar,

\footnotetext{
${ }^{13}$ As referidas perguntas faziam parte dos questionários semiestruturados aplicados no programa de formação continuada.
} 


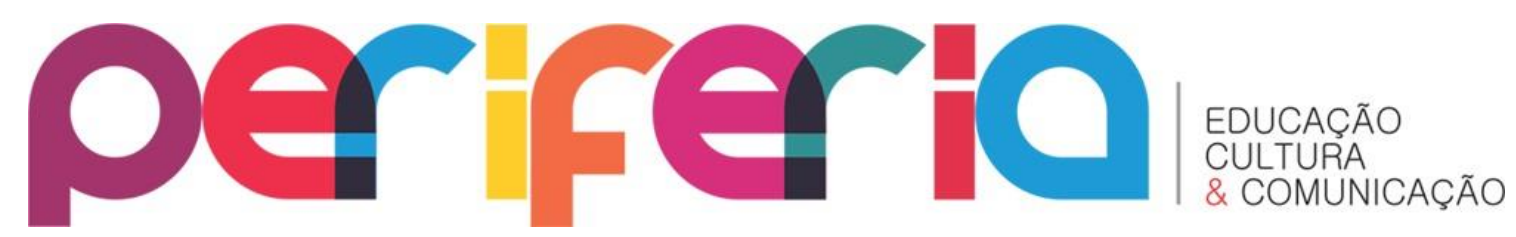

baseadas na pergunta geral que foi feita: "Você já ouviu falar de..." essa mesma pergunta foi utilizada para todos os conceitos.

A única diferença de abordagem se deu no conceito de mediação, pois além de questionar se os docentes já tinham ouvido falar sobre o conceito, também foi pedido que o mesmo relatasse dois exemplos do uso da mediação em sua prática docente em sala de aula. Dentre os $107^{14}$ questionários analisados a maioria dos docentes disseram já ter ouvido falar sobre a perspectiva histórico-cultural (100) de Vigotski e o conceito de mediação (97). Contudo, em relação a conceitos considerados mais complexos da perspectiva observamos que a maioria não ouviu falar, como, por exemplo, no caso dos processos psicológicos superiores (60).

Nas respostas discursivas em que pedíamos para definir com suas próprias palavras os conceitos os profissionais da educação demonstraram muita dificuldade e poucos conseguiram elaborar uma resposta que remetesse a perspectiva histórico-cultural. No caso da mediação, a maior dificuldade dos professores, foi em identificá-la em sua prática pedagógica, fato que consideramos preocupante, visto que, o princípio de toda pratica pedagógica é a mediação. Além disso, muitos profissionais da educação, confundiram o conceito com o profissional mediador ${ }^{15}$.

De modo geral, os dados obtidos ao final do programa de formação continuada referente as concepções dos profissionais da educação, foram muito positivos. Percebemos que todos os docentes que finalizaram o curso se apropriaram de fato dos conceitos trabalhados ao longo da formação. Acreditamos que o formato escolhido para o programa de formação continuada foi determinante para que os professores conseguissem de fato se apropriar dos conceitos trabalhados, visto que o curso foi pensado e organizado diante as demandas desses profissionais, levando em conta o

\footnotetext{
${ }^{14}$ Apesar do número total de inscritos no curso ter sido 120 , no primeiro dia, somente 107 profissionais estavam presentes e responderam ao questionário semiestruturado aplicado.

${ }^{15}$ Profissional que dá um suporte exclusivo ao aluno com deficiência incluído em sala comum de ensino. Outros termos são utilizados para se referir a esse profissional como: estimulador, cuidador, entre outros.
} 


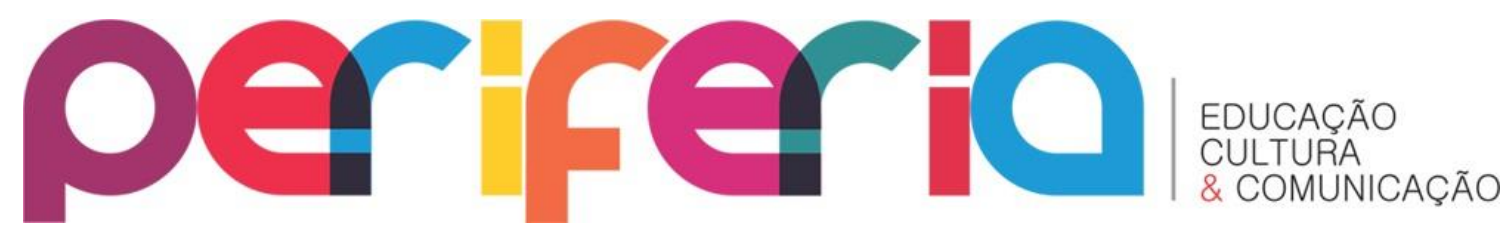

contexto da Baixada Fluminense assim como os conhecimentos que tais profissionais expressaram ter interesse no início do curso.

Um dado que consideramos muito significativo foi a mudança de padrão das respostas sobre o conceito de mediação. Ao final do curso, todos os docentes apresentaram uma perspectiva condizente com o conceito de mediação da perspectiva histórico-cultural. Para ilustrar a nossa discussão elaboramos a tabela a seguir:

Quadro 4: Respostas do público participante do Programa de Formação Continuada sobre o conceito de mediação

\begin{tabular}{|l|l|}
\hline \multicolumn{1}{|c|}{$\begin{array}{l}\text { Respostas iniciais sobre o conceito de } \\
\text { mediação }\end{array}$} & \multicolumn{1}{|c|}{$\begin{array}{c}\text { Respostas finais sobre o conceito de } \\
\text { mediação }\end{array}$} \\
\hline $\begin{array}{l}\text { Auxilia o professor e aluno na inclusão do } \\
\text { aluno. E a família. }\end{array}$ & $\begin{array}{l}\text { O ser humano no processo de } \\
\text { desenvolvimento precisa da mediação para } \\
\text { conhecer o mundo que o cerca. O deficiente } \\
\text { intelectual necessita dessa mediação com } \\
\text { maior frequência para o desenvolvimento do } \\
\text { corpo e do cognitivo. Isso acontece com } \\
\text { ajuda dos pais, familiares, professores e } \\
\text { especialistas. }\end{array}$ \\
\hline $\begin{array}{l}\text { Profissional que acompanha o aluno } \\
\text { incluído no ambiente escolar, fortalecendo } \\
\text { seus laços com a escola: cognitivo afetivo, } \\
\text { social, em comum união com o professor } \\
\text { regular. }\end{array}$ & $\begin{array}{l}\text { Mediação é o processo através do qual alguém } \\
\text { acessa o conhecimento. O instrumento dessa } \\
\text { mediação pode ser outro indivíduo ou } \\
\text { instrumentos como livros, computadores e } \\
\text { outros. }\end{array}$ \\
\hline $\begin{array}{l}\text { O mediador é um facilitador no } \\
\text { conhecimento. Ajuda o aluno incluído no } \\
\text { processo de ensino aprendizado. }\end{array}$ & $\begin{array}{l}\text { Mediação é o processo que se estabelece } \\
\text { entre o conhecimento e o indivíduo que quer } \\
\text { apropriar-se do mesmo. Nesse processo de } \\
\text { busca surge o professor que auxilia nessa } \\
\text { mediação. }\end{array}$ \\
\hline
\end{tabular}

Fonte: Elaborado por Lima (2017) a partir do Banco de dados do ObEE.

Ao observarmos as respostas iniciais e finais é evidente a apropriação do conceito de mediação pelos profissionais da educação. Diante os resultados positivos, enfatizamos que cursos dessa envergadura, necessitam ser mais disseminados pelas redes de ensino da Baixada Fluminense. Além de serem pensados frente as demandas impostas pelo contexto desses profissionais, também precisam ser um espaço de troca de conhecimentos entre as diferentes redes de ensino que compõem a Baixada, visto que esta troca de saberes é fundamental para o avanço de práticas pedagógicas cada vez mais 


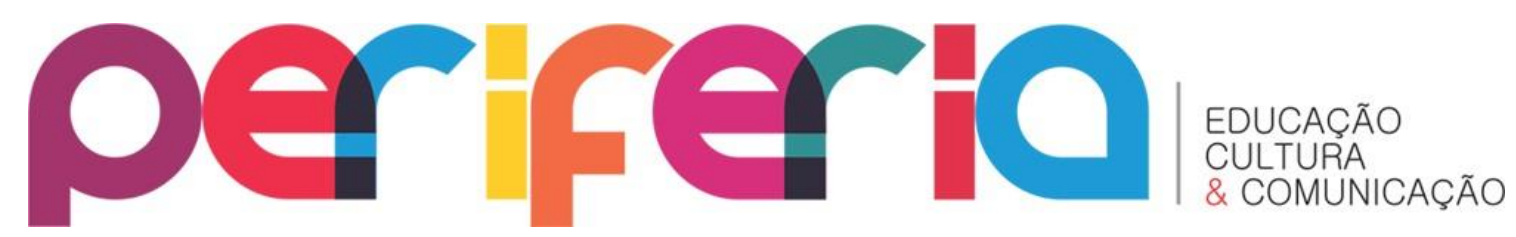

inclusivas, assim como para a articulação de estratégias que possam superar as dificuldades encontradas no dia a dia da escola. Igualmente destacamos a importância de propostas de formações continuadas que articulem pesquisa e extensão a partir da interação entre a Universidade e a Educação Básica.

\section{CONSIDERAÇÕES FINAIS}

0 artigo em questão buscou discutir a formação continuada de professores diante das atuais políticas de inclusão escolar e suas demandas, tomando como referência o Programa de Formação Continuada "Processos de ensino e aprendizagem de alunos com deficiência intelectual", desenvolvido pelo Grupo de Pesquisa Observatório de Educação Especial e Inclusão Educacional (ObEE/UFRRJ), as quais foram amplamente analisadas e discutidas nas pesquisas de Araújo (2016) e Lima (2017).

Os dados iniciais mostraram que ainda há professores atuantes no atendimento educacional especializado que não possuem nenhuma formação em educação especial ou educação inclusiva, o que implica diretamente na escolarização dos alunos com deficiência.

No que se refere a formação em educação especial oferecida aos profissionais das redes municipais de educação participantes dos projetos de pesquisa, os resultados indicaram que a maioria das formações recebidas pelos docentes eram pontuais com temas, em que não ocorria processos contínuos e avaliações sobre o impacto dessas no cotidiano das escolas. Os poucos municípios que tiveram formações que priorizaram a prática de um trabalho final como forma de avaliação e carga horária elevada, foram aqueles com em que existia parceria com instituições superiores de ensino. Essas, por sua vez, articulavam ações de formação continuada por meio de extensões em diálogo com a pesquisa.

Ainda sobre a formação dos professores pelo Programa, os dados indicaram inicialmente a fragilidade de conhecimentos destes sobre a importância de suas mediações, sobretudo, frente às demandas da inclusão de 


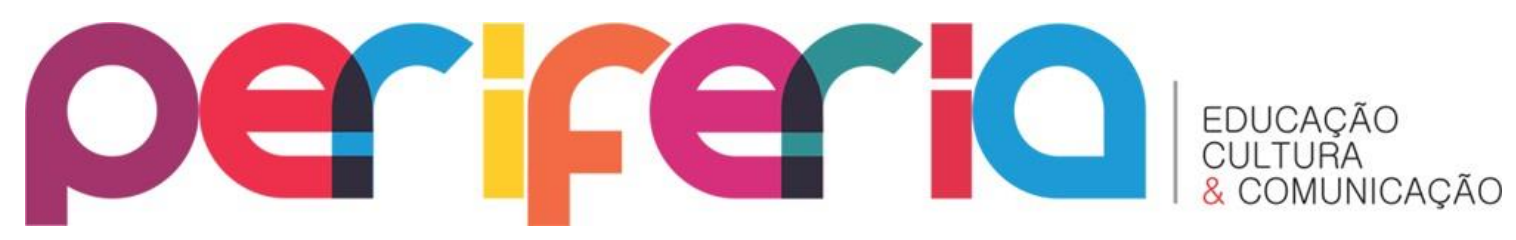

alunos com deficiência intelectual em turmas comuns de ensino já formadas por uma enorme diversidade de sujeitos. A este respeito, cabe dizer, que além da falta de conhecimento dos docentes, suas práticas também podem ser comprometidas pela escassez de formação continuada, inexistência do trabalho colaborativo aliada a longas jornadas de trabalho e a má remuneração, entre outros fatores (LIMA, 2017). Diante dessa conjuntura, acreditamos que formações continuadas de professores com vistas a participação ativa dos docentes e à autoanálise, cujo próprio professor é pesquisador da sua prática são mais eficazes e qualitativamente contribuem de forma positiva para o desenvolvimento profissional, assim como impactam na melhoria da qualidade educacional dos seus alunos, sejam eles com ou sem deficiência.

Diante dessas considerações, o Programa de Formação Continuada foi avaliado pelos participantes como positivo quanto à aquisição de conhecimentos. De acordo com a maioria, a abordagem na perspectiva histórico-cultural impulsionou o confronto de ideias, o diálogo sobre as realidades e a troca de experiências que muito se fizeram presentes nos debates e discussões durante o Programa, contribuindo significativamente para mudanças conceituais. Igualmente, sinalizaram que a formação continuada possibilitou ampliar caminhos e possibilidades sobre a aprendizagem dos alunos com deficiência intelectual.

Por fim, consideramos que a experiência de formação continuada de professores aliando extensão e pesquisa, por meio do trabalho colaborativo entre a Universidade e a Educação Básica, se mostrou como uma possibilidade real para contribuir com a formação e o debate docente na direção do fortalecendo a perspectiva de uma escola mais inclusiva e democrática. 


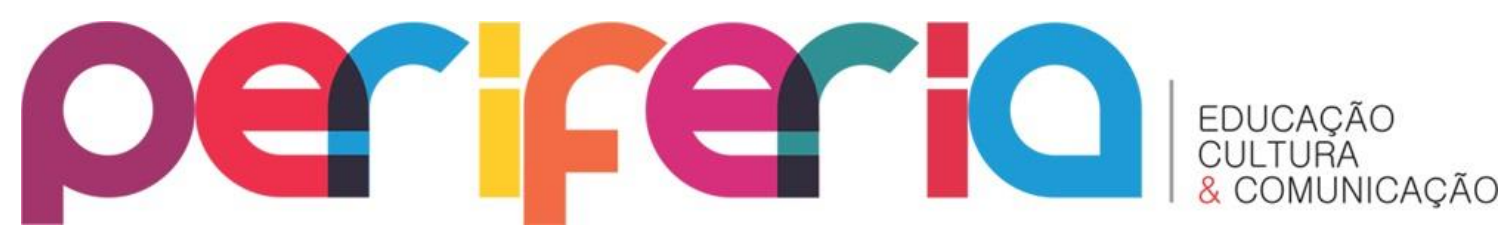

\section{REFERÊNCIAS}

AADID. American Association on Intellectual and Developmental Disabilities. Intellectual disability: definition, classification, and systems of supports. Washington, DC: AAIDD, 2010.

AVILA, L. L. de. O Planejamento Educacional Individualizado (PEI) para pessoas com deficiência intelectual: uma construção colaborativa.195 p. Dissertação (Mestrado em Educação) Instituto de Educação/Instituto Multidisciplinar/PPGEduc/Universidade Federal Rural do Rio de Janeiro, Nova Iguaçu, RJ. 2015.

.; TRIGUEIRO, M. M.; SILVA, C. D. Formação continuada colaborativa na construção do Planejamento Educacional Individualizado (PEI) para estudantes com deficiência em Belford Roxo/RJ. VII Congresso Brasileiro de Educação Especial e X Encontro Nacional dos Pesquisadores em Educação Especial. 2016.

ARAÚJO, D. F. de. Formação continuada de professores na perspectiva da educação inclusiva na Baixada Fluminense.Dissertação (Mestrado em Educação, Contextos Contemporâneos e Demandas Populares) - Universidade Federal Rural do Rio de Janeiro, 154 f., 2016.

BRASIL. Comitê de Ajudas Técnicas. ATA V. 2007. Disponível em: <www.mj.gov.br/sedh/ct/corde/dpdh/corde/comite_at.asp $>$. Acesso em: jan. 2014.

BRASIL. Política Nacional de Educação Especial na perspectiva da Educação Inclusiva. Brasília, janeiro de 2008.

BRASIL.Diretrizes Operacionais para o Atendimento Educacional Especializado na Educação Básica, modalidade Educação Especial. Resolução 4. Brasília, 2009.

BRASIL. Principais indicadores da educação de pessoas com deficiência, 2015. Disponível

em:http://portal.mec.gov.br/index.php?option=com_docman\&tview=download Ealias=17655-secadi-principais-indicadores-da-educacao-

especial\&category_slug=junho-2015-pdf\&Itemid=30192 Acessado em: abril de 2016

. Resolução $n^{\circ} 2$, de $1^{\circ}$ de julho de 2015 a.

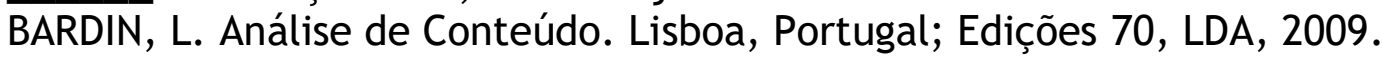




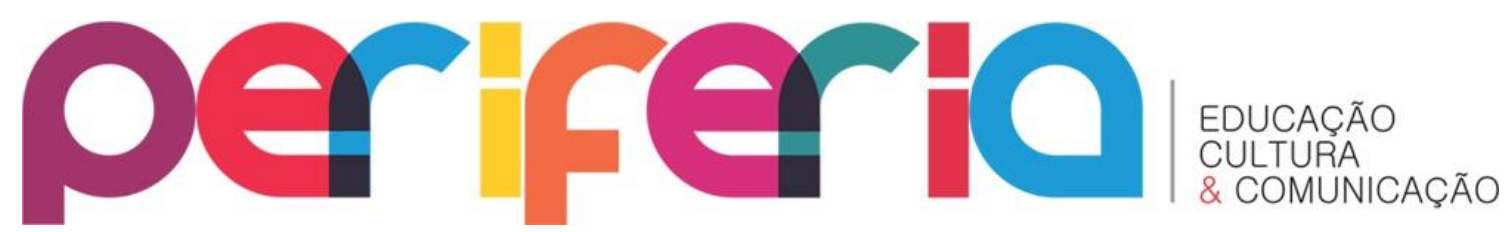

BRAUN, P. Uma intervenção colaborativa sobre os processos de ensino e aprendizagem do aluno com deficiência intelectual. Tese (Doutorado) Universidade do Estado do Rio de Janeiro, 324 f., 2012.

BRAUN, P.; MARIM, M. Ensino colaborativo: uma possibilidade do Atendimento Educacional Especializado. In: Revista Linhas da UDESC, v. 17, nº. 35, p. 193215, set./dez. 2016. Disponível em:

http://www.revistas.udesc.br/index.php/linhas/article/view/1984723817352 $\underline{016193}$ Acessado em abril de 2017.

CAMPOS. É. C. V. Z.. Diálogos entre o currículo e o planejamento educacional individualizado (PEI) na escolarização de alunos com deficiência intelectual.196 p. Dissertação (Mestrado em Educação) Instituto de Educação/Instituto Multidisciplinar / PPGEduc / Universidade Federal Rural do Rio de Janeiro, Nova Iguaçu, RJ. 2016.

FERREIRA, M. C. C. O desenvolvimento profissional do docente e a inclusão escolar de alunos com deficiência mental. In: MANZINI, E. J. (Org.). Inclusão do aluno com deficiência na escola: os desafios continuam. ABPEE/FAPESP, Pp. 13-24, 2007.

KASSAR, Mônica de C. M. Funções mentais superiores e a formação da consciência em sujeitos com deficiência mental grave: implicações pedagógicas. In: SMOLKA, Ana Luiza B.; NOGUEIRA, Ana Lúcia H. (Org.). Estudos na perspectiva de Vigotski:gênese e emergência das funções psicológicas. Campinas, SP: Mercado das Letras, 2013. p. 151-172.

KASSAR, M. C. M. Escola como espaço para a diversidade e o desenvolvimento humano. In: Revista Educação e Sociedade, v. 37, n 137, p. 1223-1240, out./dez., 2016.

LIMA, M. F. C. O que significa mediar o processo de escolarização de alunos com deficiência intelectual? Dissertação (Mestrado em Educação). Universidade Federal Rural do Rio de Janeiro. 2017.

MARIN, M. Inclusão escolar de alunos com necessidades educacionais especiais no segundo segmento do ensino fundamental em um espaço de excelência acadêmica. 2015. 194f. Tese (Doutorado) - Universidade do Estado do Rio de Janeiro. Rio de Janeiro, 2015.

MENDES, E. G.; TANNÚS-VALADÃO, G.; MILANESI, J. B. Atendimento educacional especializado para estudante com deficiência intelectual: os diferentes discursos dos professores especializados sobre o que e como ensinar. Revista Linhas. Florianópolis, v. 17, n. 35, p. 45-67, set./dez. 2016. 


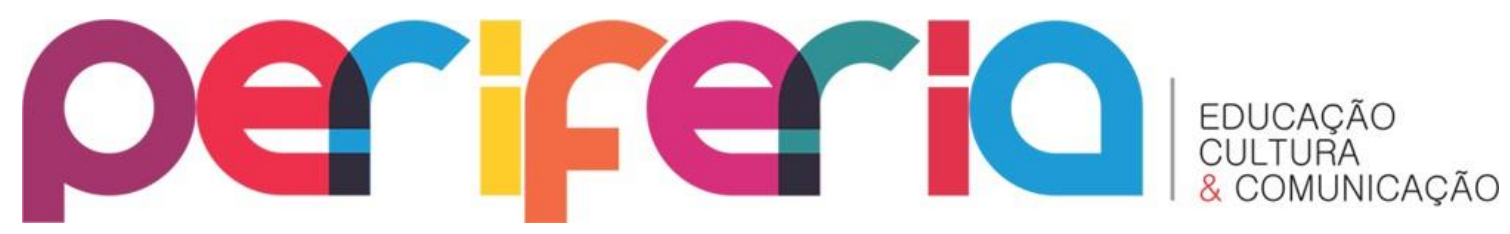

OBSERVATÓRIO DE EDUCAÇÃO ESPECIAL E INCLUSÃO EDUCACIONAL. Banco de dados. Nova Iguaçu, 2009-2016.

PLETSCH, M. D.; MENDES, G. L. M.; HOSTINS, R. L. A escolarização de alunos com deficiência intelectual: políticas públicas, processos cognitivos e avaliação da aprendizagem. Projeto de Pesquisa. Nova Iguaçu, 2012-2017.

PLETSCH, M. D. A escolarização de pessoas com deficiência intelectual no Brasil: da institucionalização às políticas de inclusão (1973-2013). In: Revista Arquivos Analíticos de Políticas Educativas, 22(81). Dossiê Educação Especial: diferenças, currículo e processos de ensino e aprendizagem. Editoras convidadas: Márcia Denise Pletsch \& Geovana Mendonça Lunardi Mendes. Disponível em: http://epaa.asu.edu/epaa/v22n81. Acessado em agosto de 2014.

PLETSCH, M. D. Deficiência múltipla: formação de professores e processos de ensino-aprendizagem. In: Revista Cadernos de Pesquisa, v. 45, p. 12-29, 2015. Disponível em:

http://www.scielo.br/scielo.php?script=sci_arttext\&pid=S0100$15742015000100012 \&$ lng=pt\&tlng=pt. Acessado em maio de 2017.

PLETSCH, M. D. Escolarização e desenvolvimento de alunos com deficiência intelectual e múltipla na Baixada Fluminense. Projeto de Pesquisa. Nova Iguaçu, 2015-2018.

PLETSCH, M. D. Educação Especial e inclusão escolar nos planos municipais de educação da Baixada Fluminense: avanços, contradições e perspectivas. In: Revista Comunicações (UNIMEP), v. 23, nº 3, p. 81-95. Disponível em: https: / /www.metodista.br/revistas/revistasunimep/index.php/comunicacoes/article/view/2951/1849 Acessado em abril de 2017. 